\title{
Documento
}




\section{Amazônia: questões e responsabilidades}

\section{ALAIN RUELLAN}

$\mathrm{N}$ o mundo inteiro, a degradação do meio ambiente atinge, cada vez mais freqüente e cada vez mais seriamente, os direitos e as liberdades dos povos: os ecossistemas e os recursos de que esses povos necessitam -são progressivamente destruídos. Por outro lado, a degradaçáo do meio ambiente é cada vez mais amiúde um fenômeno mundial, que nenhum país, mesmo entre os maiores, pode mais enfrentar sozinho. Todos os países tornaram-se dependentes uns dos outros $e$ nenhum país tem mais o direito de fazer sozinho opçóes econômicas e tecnológicas que arrisquem pôr em perigo o meio ambiente mundial. Isso é particularmente verdadeiro para os países desenvolvidos, para os países do Norte, que são os principais responsáveis pela situação degradada do meio ambiente mundial; mas isso também é verdadeiro para os países subdesenvolvidos, que é preciso pois sustentar, ajudar, a fim de que eles possam se desenvolver, sem com isso prejudicar o seu próprio meio ambiente e o meio ambiente mundial.

É neste contexto que se coloca o problema da Amazdnia.

Espero, no decorrer de minha intervenção, cujo caráter, pretendo, seja sintético, insistir sobre três aspectos do problema amazônico:

- a Amazônia é, antes de tudo, os povos;

- a Amazônia é, também, as imensas riquezas naturais;

- Finalmente, a floresta amazônica é um fator de equilíbrio a níveis local, regional e mundial.

1 - A Amazonia 6 , antes de tudo, os povos.

Falou-se bastante a respeito durante esta sessão do Tribunal.

Povos antigos, os indígenas: eles formavam, provavelmente, vários milhóes antes da chegada dos portugueses e dos espanhóis; hoje, enquanto povos que lutam por sua autonomia e sua identidade, năo sáo mais do que algumas dezenas de milhares cuja existência e os direitos continuam a ser ridicularizados.

Mas, também, populações novas que contam vários milhōes. Populaçōes novas, mas miseráveis, vindas de fora a pedido dos governos, 
para tornar produtiva a Amazônia e aí encontrar riqueza: são hoje em, dia camponeses sem terra (posseiros), coletores de látex de hevea (seringueiros), exploradores de ouro (garimpeiros)... migrando através da Amazônia, explorados ou perseguidos por aqueles que destroem esta região para se enriquecer o mais rapidamente possível; acabam mortos de esgotamento, ou assassinados, ou nos acampamentos que se multiplicam por toda a Amazônia.

Quero insistir em dois pontos:

- Esses povos, no que diz respeito aos mais antigos, constituem, por si mesmos e pelos saberes que têm, pelos conhecimentos que têm do meio amazônico, pelos conhecimentos que têm das melhores condiçóes possíveis de utilização do meio amazônico, uma riqueza considerável: essa riqueza é destruída, assassinada, pois ela não é utilizável por aqueles que querem ganhar muito dinheiro muito rapidamente.

- Essas populaçóes, no que toca às mais recentes, năo conhecem o meio amazônico; nele se perderam e, em consequiência, são levadas a fazer qualquer coisa para sobreviver; resultado: elas destroem. É preciso ajudá-las a viver sem destruir. O governo brasileiro, com o apoio das sociedades privadas nacionais e multinacionais, é culpado de explorar essas populações ao invés de ajudá-las e protegê-las; o governo brasileiro é culpado de tornar essas populaçōes destruidoras de recursos ao invés de torná-las exploradores inteligentes.

\section{2 - A Amazonia é, também, as imensas riquezas naturais.}

Reservas minerais consideráveis, cuja exploração intensiva acaba justamente de começar (Carajás,...). Um potencial de solo, malconhecido, mas que sabemos estar longe de ser desprezível: $4 \%$ do potencial hidrelétrico mundial. A maior diversidade e o mais forte potencial biológico do mundo: os recursos existentes e potenciais da Amazônia nos domínios alimentares, médicos, energéticos, materiais são enormes. $O$ drama é que esta riqueza, ainda vastamente desconhecida, é objeto de todas as cobiças.

\section{a - Iniciemos pelo subsolo.}

A Amazônia, antes de tudo, é uma fantástica reserva mineral, cuja exploração intensiva acaba de começar. Ferro, cobre, manganês, alumínio, níquel, estanho, titânio, tungstênio, urânio, sal-gema,... ouro, diamante; talvez um dia, petróleo. A última jazida a ser explorada foi a de Carajás, no Pará; descoberta em 1967, passou a ser explorada em 1985, graças ao apoio de inúmeros capitais estrangeiros. Sua riqueza é fabulosa. As condiçóes em que se processou a exploração das riquezas minerais de Carajás são representativas do que se passa em toda a Ama- 
mens e dos povos eram perfeitamente conhecidas dos que fizeram essas escolhas e dos que as financiaram.

- ou será preciso dar-se tempo, explorar no ritmo das verdadeiras necessidades do Brasil, em funçáo dos verdadeiros meios do Brasil, dando-se tempo para aprender a explorar os minérios sem destruir os ambientes e as sociedades, dando-se tempo e meios para transformar os minerais extraídos no local? É evidente que é esta segunda soluçáo que se deveria adotar e que isso é possível: para tanto, é preciso querê-la e nela trabalhar.

b - Apesar de importantes esforgos de prospecfóes e pesquisas, sendo realizados há vinte anos, os solos amazbricos sấo ainda pouco conbecidos.

Deixando de lado as terras inundadas quase permanentemente, os igapós, cobertos por uma vegetaçáo anfíbia, distinguem-se na Amazônia dois tipos de ambientes:

- Nos baixios, ao longo dos rios e ribeiras, as várzeas: são terras aluviais, inundáveis na época das chuvas. Trata-se, aqui, dos ambientes mais ricos, tanto no plano dos solos como no do ecossistema, terrestre e aquático, que o acompanha. Estima-se aproximadamente em $86 \mathrm{mil}$ quilômetros quadrados a superfície das várzeas, no Brasil. Essas regiōes constituem a principal riqueza em solos imediatamente disponíveis e acessíveis. Pesquisas detalhadas aí são atualmente conduzidas para que seja valorizado ao máximo o conjunto do potencial ecológico (trabalhos do INPA, Instituto Nacional de Pesquisas da Amazônia).

- O resto, é a terra firme. Os solos aí são, com freqüência mas nem sempre, profundos, argilosos, bem estruturados, ricos em matéria orgânica, portanto potencialmente ricos. Mas esses solos têm três defeitos consideráveis, que é preciso conhecer, se não se quiser desperdiçar toda a produção agrícola ou florestal (plantaçôes): são solos quimicamente muito pobres, muito ácidos; são tóxicos, devido à presença de alumínio em excesso; são estruturalmente muito frágeis, uma preparaçáo malconduzida pode destrú-los e compactá-los rapidamente. Essas qualidades e esses defeitos dos solos amazônicos não têm nada de original: é o comportamento clássico de muitos solos de regiőes equatoriais e tropicais úmidas.

Pode-se, entretanto, dizer que o potencial do solo amazônico está longe de ser desprezível. É preciso saber utilizá-lo sem destruí-lo. Para tanto, é preciso fazer, aí também, um esforço enorme de conhecimento e de trabalho no terreno com aqueles que desejam utilizar os solos. 


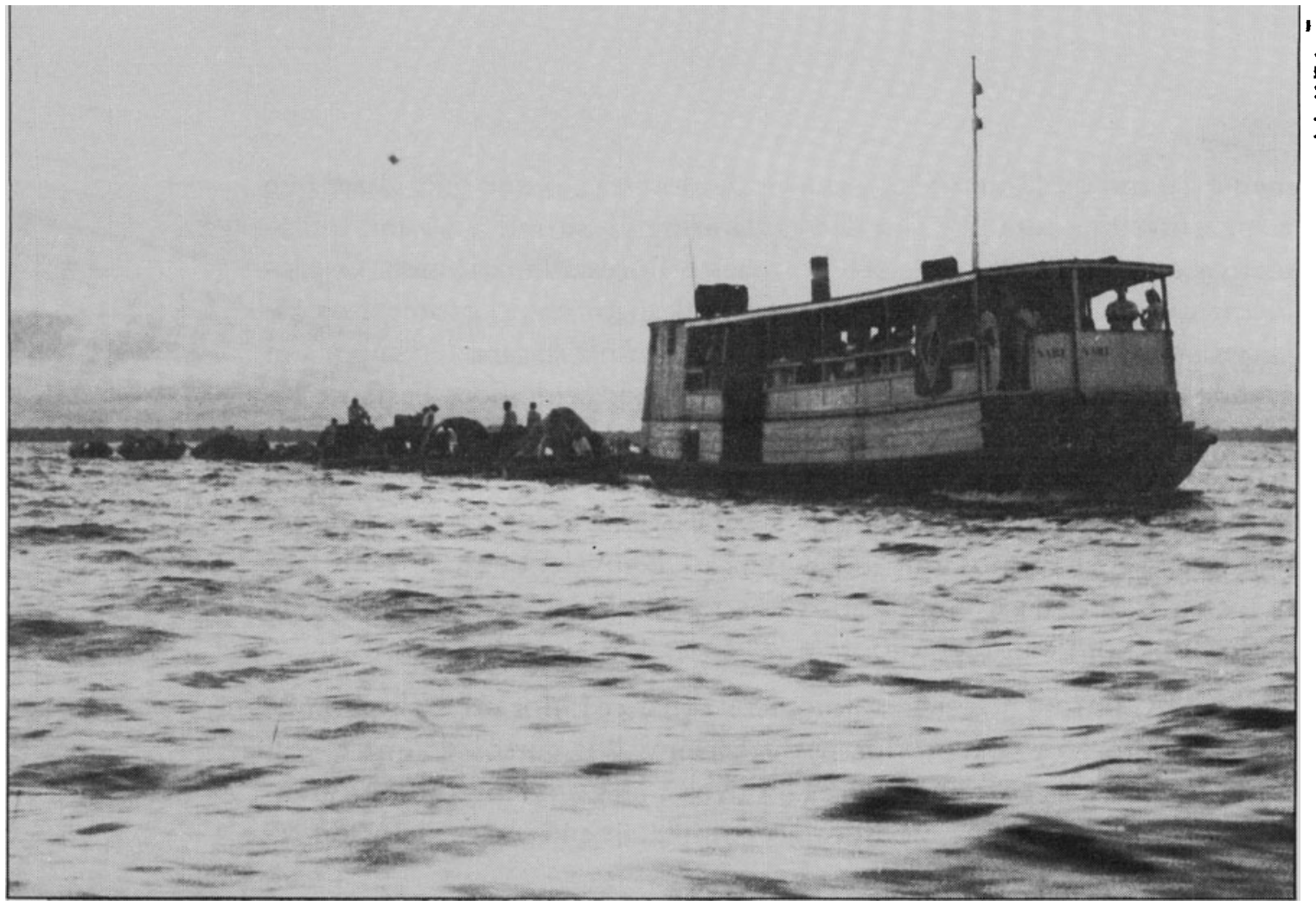

Um comboio de embarcafôes no rio Negro a caminho de Manaus. Processo classico de transporte de frutas e viveres provenientes do Parand do Careiro (Solimóes/Amazonas).

c - Terceira riqueza da Amazdnia: a energia bidrelétrica.

O potencial hidrelétrico dos rios amazônicos, o Amazonas excluído, está avaliado em $100 \mathrm{mil} \mathrm{MW}$, ou seja, $4 \%$ do potencial hidrelétrico do mundo.

A barragem do Tucuruí, represada em 1984, será, quando tiver atingido a sua plena força de 8 mil $\mathrm{MW}$, a quarta barragem do mundo. Atualmente, são construídas, em vias de construçăo ou em vias de estudos, uma dezena de barragens totalizando um potencial de $15 \mathrm{mil} \mathrm{MW}$. Quarenta outros projetos existem em dossiês.

A energia hidrelétrica é certamente indispensável ao desenvolvimento autônomo da Amazônia, de suas cidades e indústrias. Sua efetivação coloca, entretanto, um certo número de problemas, claramente identificados e que vêm sendo estudados pelos pesquisadores brasileiros:

- O deslocamento das populaçóes, em particular das populaçōes indígenas, que praticamente não são levadas em conta na elaboraçáo dos projetos.

- A destruição das florestas: considera-se que, na região de uma grande barragem, a destruição do meio natural ocorre numa área três ou quatro vezes maior do que a zona de inundação. As barragens construídas, ou em projetos a curto prazo, inundam ou inundarão aproximada- 
mente 10 mil quilômetros quadrados de florestas, o que quer dizer que a superfície que será por fim destruída atingirá 30 mil a $\mathbf{4 0}$ mil quilômetros quadrados, ou seja, $1 \%$ do maciço florestal amazônico. $O$ problema que se coloca é principalmente biológico: como proteger as espécies animais e vegetais, sabendo que a Amazônia se caracteriza por um grande endemismo: muitas espécies têm nichos ecológicos bastante localizados e específicos. Reconheçamos de passagem que, no momento do represamento da grande barragem de Tucuruí, um grande esforço foi feito para salvar todos os animais e para coletar os gráos das espécies frutíferas: gostaríamos que uma atençáo equivalente fosse dada aos homens, muito mais empurrados aos trambolhóes do que realmente deslocados com consideração.

- A ruptura dos ciclos biológicos aquáticos: por exemplo, grande número de peixes se reproduz nas cabeceiras dos cursos d'água $\mathrm{e}$, durante as cheias, as correntes carregam ovos e larvas na direşáo dos grandes eixos. As barragens modificarão completamente esses ciclos de reprodução: a pesca será afetada. $(2), \ldots$

- O desenvolvimento de certas doenças: malária, arboviroses

- Uma urbanização acelerada, que ultrapassa todas as previsōes e que se realiza em péssimas condições sociais.

Neste aspecto, ainda, podemos outra vez nos perguntar sobre a imprevisão de que dáo provas os responsáveis brasileiros e os financiadores internacionais, entre os quais o Banco Mundial, que desempenha um papel-chave.

d - Quarta riqueza: a vida, animal e vegetal.

Os ecossistemas, terrestres e aquáticos; a floresta, com suas dezenas de milhares de espécies, de plantas e de animais; os rios, com suas centenas de espécies de peixes. E a riqueza amazônica mais abundante, a mais diversificada; mas é também, de longe, a menos conhecida por aqueles que năo vivem na Amazônia $\mathrm{e}$, por isso, pela ignorância dos colonizadores, é a riqueza mais ameaçada de extinçăo, de perda total.

O inventário de espécies está longe de ser terminado; e, sobretudo, conhece-se pouco o funcionamento, as dinâmicas dos ecossistemas. Já se sabe, no entanto, muitas coisas:

- Sabe-se que o potencial genético, em plantas alimentares e medicinais, é considerável. Sabe-se disso, em particular, estudando os sistemas agrícolas tradicionais e, de modo mais geral, os sistemas de vida tradicionais dos índios e dos caboclos: a cultura de queimadas, em pe- 
ríodos de longa rotatividade (20-30 anos), a horticultura tradicional nas várzeas, os pomares ao redor das casas e das aldeias são muito diversificados, em espécies e variedades; a etnobotânica, quer dizer, o estudo das relações do homem e do seu meio vegetal, mostra a variedade de recursos em plantas úteis do meio amazônico.

- Sabe-se que a floresta vive em grande parte de si mesma; ela é debilmente enraizada, as camadas mais superficiais do solo (logo as mais frágeis) sendo essenciais para a sua regeneraçăo. Isso explica que uma floresta completamente destruída torne a crescer mal. Isso explica, também, os numerosos desastres dos sistemas agrícolas e florestais adotados, isto é, estranhos à Amazônia por sua concepçáo e por sua estrutura: por razóes dos solos, por razóes de desequilíbrio biológico, por razóes climáticas, náo se substitui facilmente a floresta amazônica, muito complexa, pelas monoculturas, sejam plantaçóes florestais, plantaçóes frutíferas, pastagens, ou culturas. O desastre mais célebre é, com certeza, o da propriedade Jari, do qual falou-se reiteradas vezes ao longo desta sessão do Tribunal. Mas há muitos outros desastres, em particular aqueles, muito mais trágicos, dos pequenos agricultores vindos de longe, perdidos nessa floresta amazônica e que nunca conseguiram sobreviver nas terras desmatadas que lhes deram ou que foram desmatadas por eles mesmos. Pode-se, em contraposiçáo, demonstrar que os sistemas agrícolas tradicionais, mesmo utilizando o fogo, valorizam sem destruir: é através da silvicultura que se pode tentar melhorar a produtividade.

\section{3 - Finalmente, a floresta amazbnica é um fator de equilibrio local, regio. nal, mundial.}

O papel dessa floresta nos ciclos da água e do carbono é ainda pouco conhecido, mas provavelmente considerável. $50 \%$ das chuvas que caem sobre a Amazônia provêm da evaporação das florestas cujo desaparecimento implicaria provavelmente climas regionais mais áridos. Por outro lado, o meio vegetal amazônico contém o equivalente a 5 a $10 \%$ do gás carbônico presente na atmosfera: a liberaçáo na atmosfera desse carbono vegetal contribuiria amplamente para $o$ aumento do efeito estufa a nível mundial.

As riquezas da floresta dificilmente são substituíveis. Uma grande parte da diversidade genética e de recursos (alimentares, médicos, etc.) perde-se definitivamente quando a floresta é destruída. Monocultura nenhuma, florestal, frutífera, agrícola, animal, chega a ter um nível de produção tão elevado quanto a floresta. $O$ desafio moderno é aprender a explorar, a cultivar os recursos renováveis da floresta, sem destruir nem modificar sua diversidade. 
Finalmente, as bases das nossas reflexōes e de nossas açóes políticas e profissionais devem, ao menos, ser as seguintes:

- A Amazônia é rica, de uma riqueza em grande parte renovável, de uma riqueza que pode ser valorizada sem desaparecer e sem abandonar suas funções ecológicas mundiais.

- A exploração das riquezas amazônicas é uma necessidade para os povos antigos e recentes que lá vivem, assim como para os países dessas regióes.

- A destruição do meio amazônico, que se produz atualmente à razão de 10 a 20 milhŏes de hectares por ano (a superfície total do maciço florestal amazônico era de $\mathbf{5 8 0}$ milhóes de hectares; quase $\mathbf{1 0 \%}$ já foram destruídos), é perigosa, verdadeiramente mortal, para os povos que aí vivem; ela é um atentado à soberania atual e futura dos estados amazônicos; ela contribui para agravar o desequilíbrio ecológico mundial, cujas primeiras vítimas sáo sempre as populaçóes mais pobres e as mais exploradas.

- A solidariedade internacional deve denunciar a gravidade do que ocorre atualmente na Amazônia, procurando as responsabilidades locais e mundiais. Mas a solidariedade internacional deve, também, denunciar todas as soluçóes que gostariam de fazer da Amazônia uma reserva; ela deve, ao contrário, contribuir com todas as açōes, científicas, técnicas, políticas que farão da Amazônia uma fonte renovável de riquezas num mundo em inelutável desenvolvimento.

É preciso aprender a conciliar a utilização dos recursos amazônicos e a não-destruição do ecossistema amazônico e das sociedades que lá vivem e dele vivem.

Isto é possível. Mas exige o respeito e o tempo.

$O$ respeito aos direitos dos popos que vivem na Amazdnia. O respeito aos saberes desses povos: para o futuro de uma utilizaçáo inteligente, produtiva e não-destrutiva da Amazônia, é indispensável apoiar-se nos saberes dos povos que aí vivem há tanto tempo: os índios, os seringueiros, os caboclos.

O tempo da pesquisa cientifica, o tempo da aquisifão de conbecimentos novos, o tempo da experimentaf̧á. $\mathrm{O}$ mundo moderno náo conhece a Amazônia. O mundo moderno, que destrói o meio amazônico, não conhece, ou conhece mal, esse meio: o inventário não foi feito, os funcionamentos não são conhecidos, as conseqüências das destruiçóes não podem ser previstas, alternativas à destruição não podem ser elaboradas; em suma, os direitos das populaçóes atuais e futuras não podem estar 
assegurados.

$O$ tempo de transfortncia de conbecimentos para aqueles que deles necessitam, em particular, as populaçóes que chegaram recentemente.

É preciso obter do governo brasileiro:

- de um lado, que a pesquisa científica, brasileira e internacional, que já trabalhou muito, seja respeitada, quer dizer, que seus numerosos resultados sejam seriamente levados em conta, antes de inventar projetos ditos de desenvolvimento, os quais, em geral, somados aos projetos de exploração e pilhagem, são projetos totalmente inadequados às realidades amazônicas;

- de outro lado, que a pesquisa brasileira concernente à Amazônia seja realmente desenvolvida, e que ela seja elaborada na Amazônia, com o apoio do conjunto da comunidade científica brasileira e internacional; as condiçôes de trabalho dos pesquisadores amazônicos devem ser seriamente melhoradas e a importância dessa pesquisa deve ser aumentada consideravelmente. É preciso, sobretudo, lembrar que a boa pesquisa sobre a Amazônia só terá validade e aplicabilidade quando feita por investigaçóes de campo, sérias e suficientemente demoradas. A credibilidade das pesquisas será tanto maior quando, em sua maior parte, ela for realizada a partir de Belém, Manaus, Boa Vista, Marabá, Rio Branco, Macapá ou Santarém.

\section{Notas}

1 CCE: é provável que esta sigla signifique Caisse Commune Europénne, que tem a finalidade de ajudar os paises subdesenvolvidos.

2 Arboviroses: viroses transmitidas por insetos (febre amarela, dengue, malária...).

Alain Ruellan é professor de Ciência do Solo, diretor do Centro Nacional de Estudos Agronómicos das Regióes Quentes do Ministério da Agricultura da França e diretor do Programa de Meio Ambiente do CNRS (Centro Nacional de Pesquisa Cientúfica, Paris).

Este texto é um depoimento do autor na sessão sobre a Amazônia brasileira, realizada pelo Tribunal Permanente dos Póvos, de 12 a 16 de outubro de 1990, em Paris.

Tradução de Maria da Glória Porto Kok. O original em francês encontra-se à disposiçáo do leitor no IEA para eventual consulta. 